\title{
The management of a patient presented with fournier's gangrene associated with undiagnosed ulcerative colitis: A
} case report

\author{
Balci B ${ }^{1 *}$, Cetindag $\mathrm{O}^{1}$, Demir $\mathrm{HB}^{1}$, Yardim $\mathrm{S}^{2}$, Calik $\mathrm{B}^{1}$ and Akbulut $\mathrm{G}^{1}$ \\ ${ }^{1}$ Department of General Surgery, Izmir Tepecik Education and Research Hospital, Izmir, Turkey \\ ${ }^{2}$ Department of Pathology, Izmir Tepecik Education and Research Hospital, Izmir, Turkey
}

\begin{abstract}
\section{Introduction}

Fournier's gangrene is a rare form of necrotizing fasciitis localized in the perineal and perianal regions, with a mortality rate ranging from $15 \%$ to $50 \%$ [1]. There are multiple causes of this polymicrobial infection including urological diseases and procedures, colorectal diseases and superficial trauma by foreign bodies. Predisposing factors are including Diabetes mellitus, chronic alcoholism, immunosuppressive diseases such as HIV infection and myeloproliferative diseases and malnutrition [2-4]. The most common isolated microorganisms are Escherichia coli and Bacteriodes [5]. The standard treatment of Fournier's gangrene is surgical debridement of the necrotic tissue and wide-spectrum antibiotics.
\end{abstract}

Introduction: Fournier's gangrene is a rare polymicrobial necrotizing fasciitis of the perineal and perianal regions, found to be associated with colorectal diseases and urogenital operations. We present here a difficult management of a patient presented with Fournier's gangrene associated with undiagnosed Ulcerative colitis.

Case presentation: A 25 year-old man presented with scrotal edema and pain was diagnosed with Fournier's gangrene. The patient was hospitalized and treated with wide-spectrum antibiotics and surgical debridement of the necrotic tissue. During follow up the patient developed a toxic megacolon which was successfully treated by colectomy and end-ileostomy. The pathological findings of the surgical specimen was resulted as a diffuse active colitis supporting ulcerative colitis.

Conclusion: Fournier's gangrene is an aggressive infection with high mortality rates which requires a multidisciplinary approach.

Fournier's gangrene complicating inflammatory bowel disease has been reported in four patients so far, two with Ulcerative colitis and two with Crohn's disease [6-9].

We present here an exceptional case management of a patient presented with a Fournier's gangrene associated with undiagnosed Ulcerative colitis.

\section{Case presentation}

A 25 year-old man complaining of the new onset of rectal pain, swelling and tenderness in the scrotum applied to the emergency service. The patient denied having abdominal pain, nausea, constipation or diarrhea. The patient had experienced rectal bleeding and mucus with defecation for three months. The patient was examined by colonoscopy in regarding of colitis and multiple biopsies were taken two days before admission to the hospital.

On physical examination bilateral scrotal congestion was significant with subcutaneaus amphysema and hyperemia. Subcutaneaus amphysema was reaching to the right groin and lower quadrant of the abdomen. In digital examination tenderness and the fluctuance was present in the right ischiorectal fossa.

In labaratory tests, leukocyte levels were 16.500 (normal limit: 4200-10.600), CRP (c-reactive protein) level was $300 \mathrm{mg} / \mathrm{L}$ and billuribine levels were $3.7 \mathrm{mg} / \mathrm{dl}$ (total billuribine) and $1.7 \mathrm{mg} / \mathrm{dl}$ (direct billuribine). AST (aspartate aminotranspharase) and ALT (alanine aminotranspharase) levels were found to be mildly elevated. Our differential diagnosis included scrotal abscess, perianal abscess and Fournier's gangrene. We decided to proceed with CT ( computer tomography) scan of the abdomen.

CT scan of the abdomen revealed subcutaneaus amphysema in the right lower quadrant reaching out the right inguinal region, right scrotum and ischiorectal fossa. Although the significant increased density and thickening in the subcutaneaus soft tissue of the abdominal wall, the peritoneum was intact (Figure 1). There were not any other pathological findings detected in the abdomen.

The patient was hospitalized with the presumptive diagnosis of Fournier's gangrene and underwent operation. The incision was started in the lower crease of the right scrotum and reached out to the right inguinal and the lower quadrant region. With the opening of the scrotum foul-smelling brown purulence discharged. The testicles were not involved. The extensive necrotic tissue debridement of the perianal and scrotal region were done including the skin and the fascia. It was also revealed that the external anal sphincters were damaged and the sphincters were primarily repaired. Necrotic tissue samples were taken for aerobic and anaerobic cultures. Vacuum assisted closure (VAC)

Correspondence to: Balci B, Department of General Surgery, Izmir Tepecik Education and Research Hospital, Izmir, Turkey, E-mail: bengibalci@gmail.com

Received: August 09, 2016; Accepted: September 05, 2016; Published: September 08, 2016 

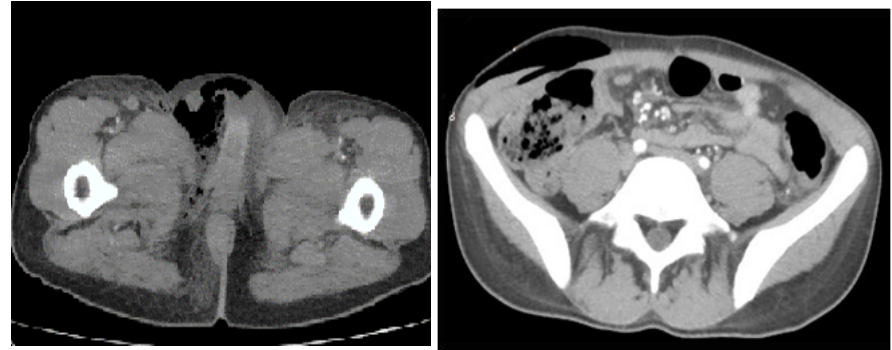

Figure 1. a) Subcutaneaus amphysema located in the right scrotum, b) Subcutaneaus amphysema of the abdominal wall.

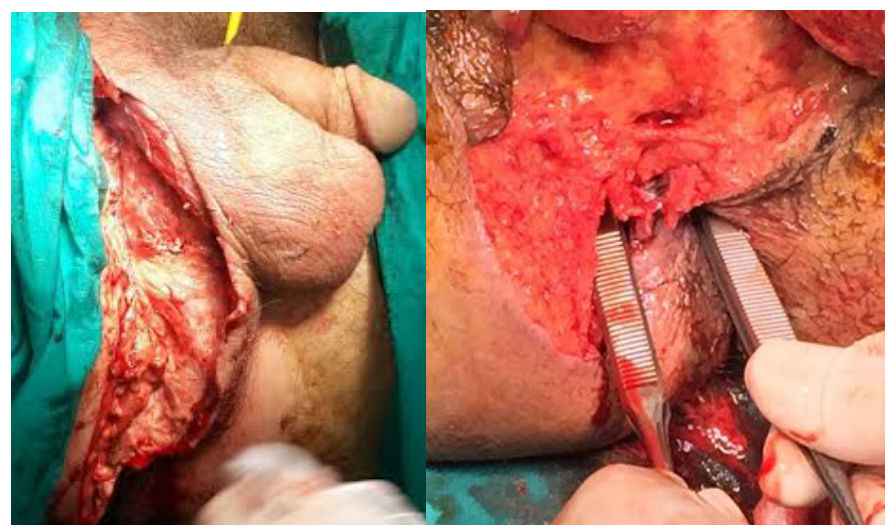

Figure 2. a) The right scrotum after surgical debridement b) The relation of the ischiorectal fossa and anal verge.

technique was chosen as the wound dressing (Figure 2).

The patient was started on broad-spectrum antibiotics with vancomycin and meropeneme. The routine follow-up were done with CBC (complete blood count), liver and kidney function tests. Although leukocyte levels decreased for first three days, then elevated to 19.500 (normal limit: 4200-10.600). Total and direct billuribine levels were elevated up to 4.9 and $2.8 \mathrm{mg} / \mathrm{dl}$. AST and ALT levels were 226 and $72 \mathrm{U} / \mathrm{L}$, ALP (alkaline phosphatase) and GGT (gamma glutamine transpharase) levels were 666 and $441 \mathrm{U} / \mathrm{L}$. CRP was measured 147 $\mathrm{mg} / \mathrm{L}$.

On postoperative $8^{\text {th }}$ day, the patient started having abdominal pain, distention and fever with septic appearence. Another CT scan of the abdomen was performed revealing distention of transverse segment of the colon up to $8-9 \mathrm{~cm}$ with extensive fluid surrounding the colonic segments. With the presumptive diagnosis of toxic megacolon, explorative laparatomy was performed (Image 5-6). Operative findings were extensive distention of the ascending, transverse and the descending segments of the colon. A perforated area was located in the transverse segment of the colon. The sigmoid colon and the rectum were intact. We decided to proceed with subtotal colectomy and endileostomy.

The patient was taken to the intensive care unite and the same antibiotic regimen with vancomycin and meropenem were continued for 13 days. CRP and procalcitonin levels were followed regularly. Cultures of the necrotic tissue samples were resulted as Acineotobacter baumanii and Pseudomanas aeroginosa. The antibiotic regimen was changed to linezolid, colistine and tazocin. The regimen was continued for 24 days.

The patients' debrided wound was continued to be dressed with VAC for 34 days. The VAC dresses were changed every 48 to 72 hours. During follow-up, septic appearence of the patient regressed. On postoperative $36^{\text {th }}$ day, the wound was partially closed by secondary suturing and the remaining part was left for spontaneous epithelialisation.

The pathological findings of the surgical specimen were mucosal ischemia and necrosis of the resected segments of the colon. There were multiple mucosal ulcerated lesions, cryptic distortions, and significant lymphoid infiltration with aggregate formation consistent with inflammatory bowel disease. All of the dissected lymph nodes were found to be reactive (Figure 4).

Also the pathological findings of the colonoscopic biopsies were found to be similar, with increasing cryptitis formation and lymphoid infiltration in mucosa of the distal segments of the colon and the rectum. The granuloma formation was not detected. All these results suggested diffuse active colitis supporting ulcerative colitis.

The patient was started on salofalk and discharged on postoperative $42^{\text {th }}$ day.

\section{Discussion}

Fournier's gangrene is an aggressive necrotizing fasciitis of perianal, genitourinary and perianal regions. The source and the entrance of the infective microorganisms are commonly found to be

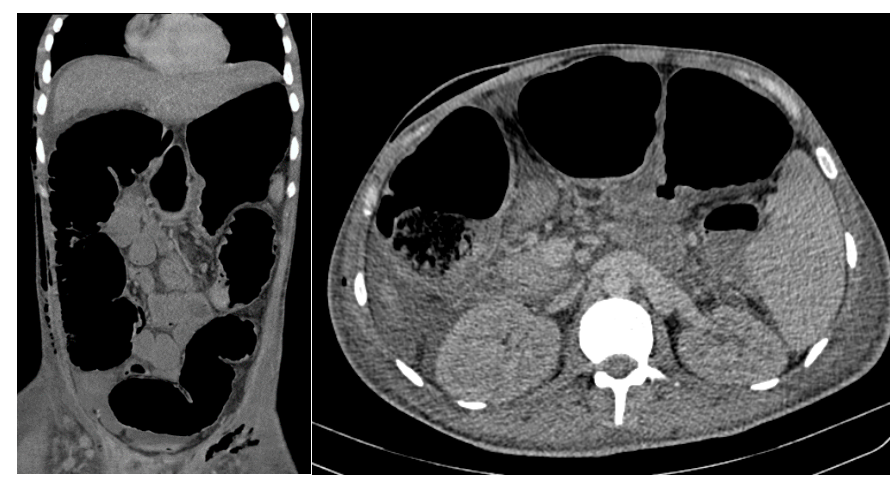

Figure 3. CT scan of the abdomen: Extensive distention of the ascending, transverse and the descending segments of the colon.
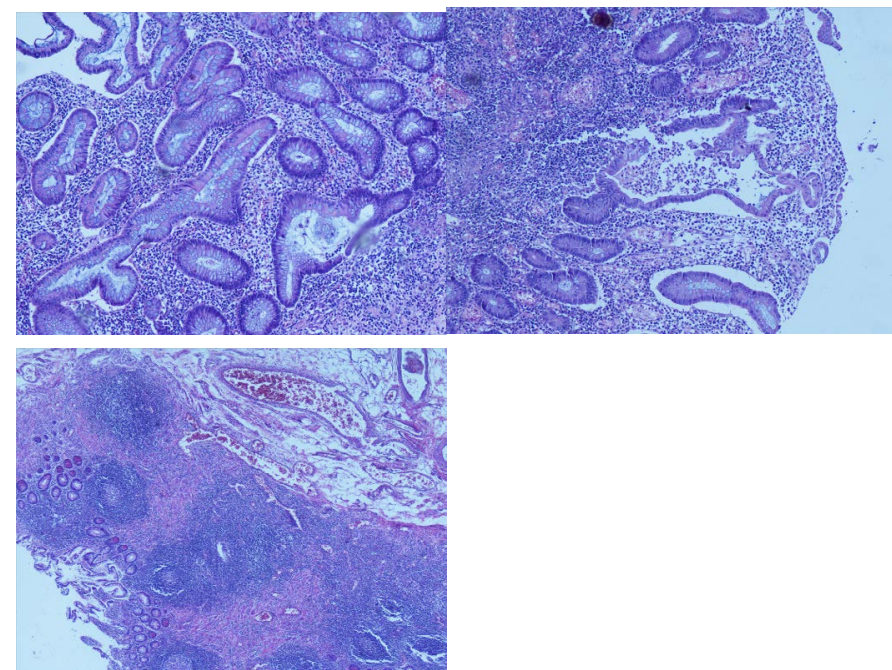

Figure 4. a) Distortions in cryptic formation, b) Ulcerated lesions, c) Cryptic abcess with lymphoid and plasma cells infiltration. 
anorectal lesions and cutaneous trauma by foreign bodies. The main predisposing factors are considered to be immunosuppressive diseases, Diabetes Mellitus and chronic alcoholism.

The case report we present here, distinguishes itself with the patients' younger age and the underlying undiagnosed ulcerative colitis which can easily mislead. Although the disease mostly effect elder patients, with recent studies the age range was found to be between 22 to 88 years old [10]. Various colorectal diseases and procedures have been associated with Fournier's gangrene; such as iatrogenic colon perforation [11], sigmoid colon perforation via dislocated pancreatic stent [12], perforation of a malignant tumor located in rectum [13].

The possible triggering factors for our patient are underlying inflammatory bowel disease and performed colonoscopy. So, a thorough evaluation for underlying disease including any previous symptoms such as rectal bleeding, loose stools and weight loss, and previous procedures should be overtaken.

The main standard treatment is surgical debridement of the necrotic tissue and wide-spectrum antibiotics, regardless of associated disease. However, in patients with inflammatory bowel disease, antiinflammatory regimens such as mesalamine, salofalk and 6-MP can also be effective in alleviating the disease. Hyperbaric oxygen therapy, various skin grafts, and vacuum -assisted closure techniques are also found to be effective in reducing the hospital stay and patients' discomfort $[14,15]$.

\section{Conclusion}

We present here an exceptional case management of a patient presented with a Fournier's gangrene associated with undiagnosed Ulcerative colitis. Fournier's gangrene is an aggressive infection with high mortality rates despite of new treatment modalities. A multidisciplinary approach is crucial for this devastating disease.

\section{References}

1. Unal B, Kocer B, Ozel E, Bozkurt B, Yildirim O, et al. (2006) Fournier gangrene. Approaches to diagnosis and treatment. Saudi Med J 27: 1038-1043.[Crossref]
2. Aschoff R, Baldauf A, Leike S, Wirth MP, Meurer M (2006) Extensive Fournier gangrene. A dermatologic emergency. Hautarzt 57: 217-8. [Crossref]

3. Vástyán A, Gulácsy I, Fazekas Z (1994) [Fournier gangrene following prostatic puncture]. Orv Hetil 135: 2039-2040.[Crossref]

4. Faber HJ, Girbes AR, Daenen S (1998) Fournier's gangrene as first presentation of promyelocytic leukemia. Leuk Res 22: 473-476.[Crossref]

5. Goyette M (1997) Group A streptococcal necrotizing fasciitis Fournier's gangrene-Quebec. Can Commun Dis Rep 23: 101-103.[Crossref]

6. Jiang T, Covington JA, Haile CA, Murphy JB, Rotolo FS, et al. (2000) Fournier gangrene associated with Crohn disease. Mayo Clin Proc 75: 647-649.[Crossref]

7. Brings HA, Matthews R, Brinkman J, Rotolo J (1997) Crohn's disease presenting with Fournier's gangrene and enterovesical fistula. Am Surg 63: 401-405.[Crossref]

8. Brings HA, Matthews R, Brinkman J, Rotolo J (1997) Crohn's disease presenting with Fournier's gangrene and enterovesical fistula. Am Surg 63: 401-405.[Crossref]

9. Katsanos KH, Ignatiadou E, Sarandi M, Godevenos D, Asproudis I, et al. (2010) Fournier's gangrene complicating ulcerative pancolitis. J Crohns Colitis 4: 203-206. [Crossref]

10. Cohen M, Tamir E, Abu-Abid S, Galili Y, Giladi M, et al. (1998) [The diagnosis and treatment of Fournier's gangrene]. Harefuah 135: 360-363, 407.[Crossref]

11. Yılmazlar T, Işıı̈Ö, Öztürk E, Özer A, Gülcü B, et al. (2014) Fournier's gangrene: review of 120 patients and predictors of mortality. Ulus Travma Acil Cerrahi Derg 20 333-337.[Crossref]

12. Papadimitriou G, Koukoulaki M, Vardas K, Grigorakis A, Vougas V, et al. (2015) Fournier's gangrene due to perioperative iatrogenic colon perforation in a renal transplant recipient. Saudi J Kidney Dis Transpl 26: 1257-61. [Crossref]

13. Schulz D, Mohor GS, Solovan C (2015) Unusual foreign body in the sigmoid colon, chronic alcohol abuse, and Fournier gangrene: a case report. ClinInterv Aging 10: 6737. [Crossref]

14. Ossibi PE, Souiki T, Ibn Majdoub K, Toughrai I, Laalim SA, et al. (2015) Fournier gangrene: rare complication of rectal cancer. Pan Afr Med J 20: 288.[Crossref]

15. Cuccia G, Mucciardi G, Morgia G, Stagnod'Alcontres F, Galì A, et al. (2009) Vacuumassisted closure for the treatment of Fournier's gangrene. UrolInt 82: 426-431. [Crossref]

16. Oguz A, Gümüş M, Turkoglu A, Bozdağ Z, Ülger BV, et al. (2015) Fournier's Gangrene: A Summary of 10 Years of Clinical Experience. Int Surg 100: 934-941.[Crossref]

Copyright: (C2016 Balci B. This is an open-access article distributed under the terms of the Creative Commons Attribution License, which permits unrestricted use, distribution, and reproduction in any medium, provided the original author and source are credited. 